\title{
Long-acting reversible contraception has no influence on weight or body mass composition
}

Keywords: long-acting reversible contraceptives, eng, LNG, LNG-IUS, IUD-cu

\section{Introduction}

Long-Acting Reversible Contraceptives (LARC) are represented by implants (with etonogestrel-ENG and levonorgestrel-LNG) and intrauterine devices (with copper and levonorgestrel). Short-acting reversible contraceptives are represented by injectables, pills, patch and vaginal ring. ${ }^{1}$ Among the LARC, levonorgestrel intrauterine system (LNG-IUS) and implants are only progestogen methods, while the intrauterine device with copper (IUD-Cu) is a non-hormonal method, and therefore often used for comparison with hormonal methods, in the studies.

The most cost-effective contraceptive methods are LARCs, because these are not user-dependent, have high rates of satisfaction and continuation and have very low failure rates (less than $1 \%$ versus around $9 \%$ in oral contraceptive pill users. ${ }^{2,3}$

Women are always afraid about weight and some of them report weight changes after started a hormonal contraceptive. A recent Cochrane's review affirmed that it is a patient misperceived perception. The review analyzed effects of progestogen-only contraceptive methods (implants, LNG-IUS, oral progesterone-only and depot medroxyprogesterone acetate-DMPA) on weight and found limited scientific evidence on changes in weight and body composition related to the use of these contraceptives. Weight gain was mainly associated with the use of DMPA, with a weight gain of less than $2 \mathrm{~kg}$ during 12 months. ${ }^{4}$

Weight gain is reported by $13 \%$ of ENG implant users ${ }^{5}$ and by $12 \%$ of users of LNG-IUS. ${ }^{6}$ Despite this, few women $(<5 \%)$ discontinue these contraceptives due to a weight gain complaint. ${ }^{7}$ Dal'Ava et al. ${ }^{8}$ observed a weight gain of $2.9 \mathrm{~kg}$ between users of LNG-IUS $(\mathrm{p}=0.0012)$, while IUD-Cu users gained $1.4 \mathrm{~kg}(\mathrm{p}=0.067)$ in 12 months. However, there was no difference between groups. This shows a "physiological" weight gain among women over the years. ${ }^{8}$

Vickery and colleagues observed, after 12 months, weight gain of $2.1 \mathrm{~kg}$ among ENG implant users, $1 \mathrm{~kg}$ among LNG-IUS users and $0.2 \mathrm{~kg}$ among IUD-Cu, with no statistical difference between groups. Concluding that there is no difference in weight gain among the users of LARC, after adjusting the confounding variables, such as age and race. Only the black race was associated with a significant increase in weight gain (1.3kg, 95\% CI: 0.2-2.4). Authors concluded that health professionals need to adequate inform patients about the no effect on weight. ${ }^{9}$

A recent study analyzed changes in body weight and body composition (percentage of body fat, total body mass, total lean mass, total body mass) among users of contraceptive implant-ENG, LNGIUS, and Cu-IUD during a year. At baseline, women had similar characteristics, including daily physical activity and eating habits. Reducing, therefore, the possibility of confounding variables in the results. Authors reported no difference in weight change and body mass index (BMI) between groups. However, there were reports of

\author{
Volume 2 Issue 5 - 2017 \\ Milena Bastos Brito \\ Adjunct Professor at Bahiana School of Medicine and Public \\ Health, Brazil
}

\begin{abstract}
Correspondence: Milena Bastos Brito,Adjunct Professor at Bahiana School of Medicine and Public Health, Science Development Foundation of Bahia,Av. D. João VI, 275 - Brotas, Salvador - BA, Brazil, Tel +55-7I- 3276-8265, Fax +55-7I- 32768202, Email milenabrito@bahiana.edu.br
\end{abstract}

Received: July 06, 2017 | Published: August 18, 2017

greater daily physical activity among ENG implant users compared to $\mathrm{Cu}$-IUD users [per day: mean difference between ENG and IUD$\mathrm{Cu}$ users $=1.67,95 \%$ confidence interval (CI): 0.006-3.20, $\mathrm{p}<0.05$; Per week: mean difference between users of ENG implant and IUD$\mathrm{Cu}=11.24,95 \%$ CI: 0.042-22.45, $\mathrm{p}<0.05$ ]. In addition, a mean increase of $0.5 \mathrm{Kg}, 0.4 \mathrm{Kg}$ and $0.1 \mathrm{~kg}$ of body weight in users of LNG-IUS, IUD$\mathrm{Cu}$ and ENG Implant, respectively, was observed after 12months, without statistical difference intra or inter groups. BMI and physical activity did not change in 12 months in any of the groups. Authors also analyzed body composition by dual energy x-ray absorptiometry (DEXA) and founded no changes in the body composition between LARCs users. The authors also observed that the black race was associated with an increase in body mass $(2.68 \mathrm{~kg}, 95 \%$ CI $0.5-4.83$, $\mathrm{p}<0.05){ }^{10}$

The two prospective, previously published studies evaluating body mass composition among LARC users demonstrated that body fat percentage increased among users of ENG and LNG-IUS implants, compared to users of the Cu-IUD. ${ }^{11}$ Another study, from the same group of researchers, also observed a $2.5 \%$ increase in fat mass among LNG-IUS users during 12 months and there was also weight gain (1.4\%) among IUD-Cu users after 12 months. ${ }^{8}$ Unlike the previous results, the most recent study published by Silva Dos Santos et al. ${ }^{10}$ showed no difference in body composition between LARCs users. ${ }^{10}$

Medical advice should be based on recent scientific evidence. The important thing is to keep the "old" orientation to all patient, independently of the contractive chosen: to stay healthy she should have a balanced diet and regular physical activity.

\section{Acknowledgements}

None.

\section{Conflict of interest}

Author declares that there is no conflict of interest.

\section{References}

1- ACOG Committee. ACOG Committee Opinion no. 450: Increasing use of contraceptive implants and intrauterine device to reduce unintended pregnancy. Obstet Gynecol. 2009;114(6):1434-1438. 
2- Winner B, Peipert JF, Zhao Q, et al. Effectiveness of long-acting reversible contraception. N Engl J Med. 2012;366(21):1998-2007.

3- C Mavranezouli I, LARC Guideline Development Group. The costeffectiveness of long-acting reversible contraceptive methods in the UK: analysis based on a decision-analytic model developed for a Nationa Institute for Health and Clinical Excellence (NICE) clinical practice guideline. Hum Reprod. 2008;23(6):1338-1345.

4- Lopez LM, Ramesh S, Chen M, et al. Progestin-only contraceptives: effects on weight. Cochrane Database Syst Rev. 2016;13(4):CD008815.

5- Blumenthal PD. Eur J Contracept Reprod Health Care. 2008;13(Suppl 1):29-36.

6- Dickerson LM, Diaz VA, Jordan J, et al. Satisfaction, early removal, and side effects associated with longacting reversible contraception. Fam Med. 2013;45(10):701-707.
7- Hohmann H, Creinin MD. The contraceptive implant. Clin Obstet Gynecol. 2007;50(4):907-917.

8- Dal'Ava N, Bahamondes L, Bahamondes MV, et al. Body weight and composition in users of levonorgestrelreleasing intrauterine system. Contraception. 2012;86(4):350-353.

9- Vickery Z, Madden T, Zhao Q, et al. Weight change at 12 months in users of three progestin-only contraceptive methods. Contraception. 2013;88(4):503-508.

10- Silva Dos Santos PN, Madden T, Omvig K, et al. Changes in body composition in women using long-acting reversible contraception. Contraception. 2017;95(4):382-389.

11- Modesto W, Dal Ava N, Monteiro I, et al. Body composition and bone mineral density in users of the etonogestrel-releasing contraceptive implant. Arch Gynecol Obstet. 2015;292(6):1387-1391. 